\title{
O desafio de ensinar modelos atômicos a alunos cegos e o processo de formação de professores
}

\author{
Renata Cardoso de Sá Ribeiro Razuck* \\ Loraine Borges Guimarães**
}

\section{Resumo}

A partir das orientações contidas na Política Nacional de Educação Especial na Perspectiva da Educação Inclusiva (2008), os alunos com necessidades educacionais especiais passaram a ser matriculados nas escolas regulares. Especificamente com relação à inclusão de alunos cegos, devido às suas características peculiares, são necessários recursos e materiais adequados que possam suprir a falta da visualização dos objetos. Nesse contexto, a Química, disciplina que utiliza grande apelo visual, oferece um enorme desafio para a aquisição dos seus conceitos pelos deficientes visuais. Com o intuito de tentar suprir algumas lacunas em conteúdos de Química com grande apelo visual, este trabalho propõe a discussão sobre a importância de se aplicar recursos pedagógicos alternativos que possibilitem aos deficientes visuais a compreensão e a construção do imaginário desta ciência, trabalhando-se para isso com protótipos sobre os Modelos Atômicos. Com este trabalho pretende-se, não apenas colaborar para o processo de ensino-aprendizagem, mas também para a formação de licenciandos mais aptos a trabalhar na perspectiva da inclusão.

Palavras-chave: Ensino de Química; Inclusão; Modelos Atômicos.

* Professora Doutora em Educação pela Universidade de Brasília, Brasília, Distrito Federal, Brasil

** Licencianda do Curso de Ciências Naturais, pela Universidade de Brasília, Faculdade UnB Planaltina, Brasília, Distrito Federal, Brasil. 


\title{
The Challenge of Teaching Blind Students Atomic Models and the Process of Teacher Education
}

\begin{abstract}
Based on the National Special Education in the Perspective of Inclusive Education (2008), students with special educational needs have to be included in the regular schools. Specifically blind students, because of their specific characteristics, they need necessary resources and suitable materials that can provide overcoming the lack of visualization. In this context, chemistry has a great visual appeal and provides a huge challenge for the acquisition of its concepts by the blinds. In order to try to fill some gaps in Chemistry contents with great visual appeal, this paper proposes a discussion on the importance of applying alternative pedagogical resources that enable visually impaired to understand and construct this imaginary science, working to this with prototypes of atomic models. This work is intended not only to contribute to the teaching-learning process, but also for the training of undergraduate courses to work towards inclusion
\end{abstract}

Keywords: Chemical Education; Inclusion; Atomic Models.

Introdução

De acordo com a Lei de Diretrizes e Bases de 1995 (Lei № 9394/96), no que se refere ao direito à educação e ao dever de educar, a aprendizagem é um direito que deve ser garantido a todos, seguindo-se os princípios da igualdade e dos direitos de oportunidades, independente de qualquer característica física, social ou cultural do indivíduo. Nesse contexto, especificamente sobre a educação especial, no seu capítulo V, art. 58, esta é entendida como uma modalidade de educação escolar, oferecida preferencialmente, na rede regular de ensino, para educandos com necessidades educacionais especiais. Porém, apesar da proclamação desta legislação, a qual esclarece os direitos dos portadores de necessidades educacionais especiais, observa-se que ainda não é garantido o acesso ao ensino regular, com as reais possibilidades de um ensino de qualidade.

Segundo Retondo e Silva (2008), apesar de crianças e adolescentes com necessidades educacionais especiais estarem frequentando classes regulares de ensino, ainda existem muitos professores que se sentem "despreparados" para trabalhar com tais alunos, o que compromete a inclusão escolar. Tal fato nos faz repensar os cursos de Licenciatura e buscar novas estratégias de formação.

Com a criação da Política Nacional de Educação Especial na Perspectiva da Educação Inclusiva pelo Ministério da Educação (BRASIL, 2008, p. 1), em 2008, entende-se que o movimento pela inclusão é "uma ação política, cultural, social e pedagógica, desencadeada em defesa do direito de todos os alunos de estarem juntos, aprendendo e participando, sem nenhum tipo de discriminação". 
Considerando-se as dificuldades de acesso à aprendizagem de alunos com deficiências, Santos (2007) lembra que no caso da cegueira, esta traz uma limitação importante ao processo de ensino, exigindo que as práticas educativas, junto às pessoas com deficiência visual, sejam pensadas de forma a contemplar suas peculiaridades, por meio das vias alternativas. Assim, alunos cegos são capazes de utilizar os demais órgãos do sentido para aprender e possuem o mesmo potencial de aprendizagem que alunos com a visão normal. Além disso, a deficiência visual é definida como a diminuição da resposta visual, que pode ser leve, moderada, severa ou profunda (que compõem o grupo de visão subnormal ou baixa visão), ou a ausência total da resposta visual (cegueira) (PIRES; RAPOSO; MÓL, 2007).

Portanto, partindo-se do princípio de que a falta da visão não interfere na capacidade intelectual e cognitiva, entende-se que os alunos cegos têm o mesmo potencial de aprendizagem, podendo, inclusive, demonstrar um desempenho escolar equivalente ou superior ao de alunos que enxergam, mediante condições e recursos adequados (CAMPOS; SÁ; SILVA, 2007).

Essa afirmação remete, também, ao ensino de Química, disciplina que se utiliza de grande apelo visual, pois muitos de seus conceitos se baseiam na visualização de esquemas para sua compreensão. Para facilitar a compreensão dos conteúdos, os livros de Química são carregados de imagens e modelos, o que pode dificultar o acesso a tais conhecimentos por alunos cegos ou com baixa visão. A utilização de imagens, como ferramenta, na compreensão de conceitos é verificada, por exemplo, no ensino de Modelos Atômicos, no qual cada modelo se associa a uma representação imagística.

No estudo da Química, muitos conceitos precisam de uma representação simbólica e o uso do Braille (sistema de escrita utilizado por pessoas cegas) muitas vezes não é suficiente para substituir uma imagem. Exatamente por isso é necessário adaptar-se materiais pedagógicos para possibilitar a aprendizagem dos alunos cegos, para que estes possam compreender e conhecer, por exemplo, os Modelos Atômicos, assunto considerado muito importante para o ensino de Química, pois favorece a elucidação de teorias científicas.

Assim, este estudo propõe a elaboração, aplicação e avaliação de recursos didáticos alternativos para o ensino de Modelos Atômicos. Entende-se que esses modelos auxiliam na construção cognitiva desses alunos, por meio de vias alternativas, como é sugerido por Vygotsky (1997).

\section{Metodologia}

Nessa pesquisa que se configurou como um trabalho de conclusão de curso de uma licencianda em Ciências Naturais, foi proposto o desenvolvimento de materiais didáticos alternativos, aqui chamados de protótipos, acessíveis ao manuseio, que simulassem os Modelos Atômicos historicamente construídos (Dalton, Thomson, Rutherford e Bohr). Os materiais propostos e utilizados para cada modelo foram: 


\section{Modelo de Dalton}

Para o modelo de Dalton foi utilizada uma bola de bilhar (figura 1), representando uma esfera maciça e indivisível (como afirmava Dalton).

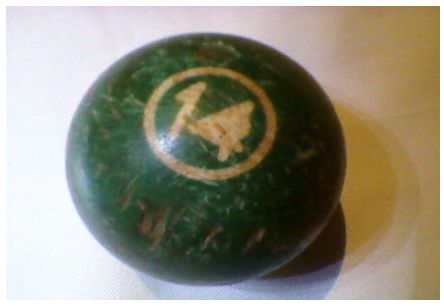

Figura 1. Foto que retrata o protótipo (bola de bilhar).

\section{Modelo de Thompson}

Para o Modelo de Thompson, descrito como uma esfera incrustada de elétrons (figura 2), foi utilizado um balão inflável (figura 3), preenchido com maisena (representando a parte positiva) e miçangas paupáveis (representando os elétrons). Quando manuseado, é possivel sentir as miçangas internas, que representam os elétrons. Também, foi utilizada uma esfera feita de massa de cimento (figura 4) com pingos de parafina em seu exterior, para representar os elétrons que também poderiam localizar-se na extremidade do "átomo".

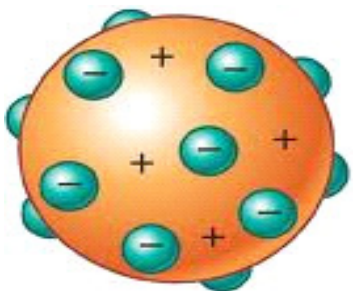

Figura 2. Modelo

deThompson. Fonte: 〈http:// latinoamericanoargentia.

blogspot.com/2010/04/ un-atomo-de-thomson depelotudeces.html.

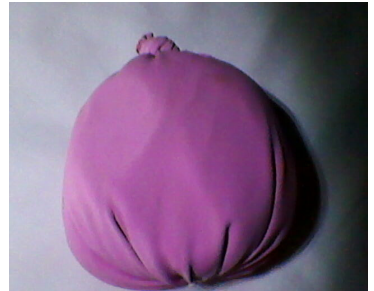

Figura 3. Foto que retrata o protótipo de Thompson, balão preenchido com maisena.

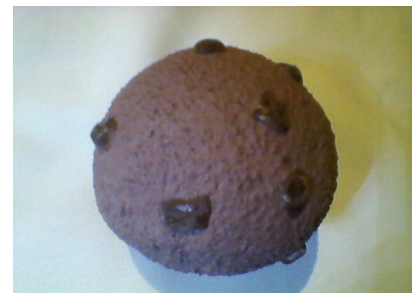

Figura 4. Foto que retrata o protótipo, esfera feita de massa de cimento. 


\section{Modelo de Rutherford}

Para o modelo de Rutherford (figura 5), foi feito um protótipo utilizando arame em círculos (representando os orbitais em torno do núcleo) e bolas de isopor para representar o núcleo. As bolas de isopor de cor branca representam os nêutrons e as de cor roxa os prótons, com textura difernciada (figura 6), para facilitar a identificação de alunos cegos, com baixa visão e videntes. Outro modelo também foi construído com a utilização de bolas de isopor e bilocas, o que permite diferenciar ainda mais a textura. Nos orbitais (representados pelos arames) há pequenas miçangas que simbolizam os elétrons (desconsiderando as proporções de tamanho, já que os elétrons são muito menores que os prótons e nêutrons).

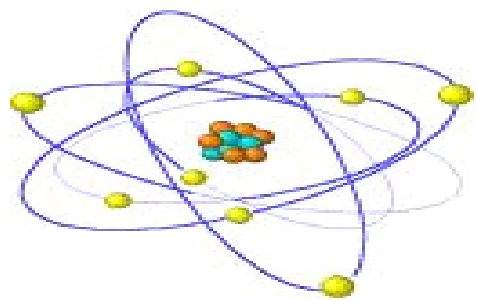

Figura 5. Modelo de Rutherford. Fonte: 〈http://coisasandthings.blogspot. com/200812_01_archive.html .

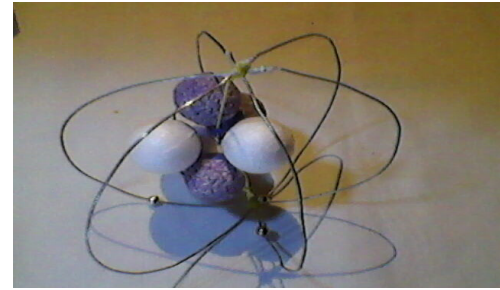

Figura 6. Foto que retrata o protótipo do Modelo de Rutherford.

\section{Modelo de Bohr}

Para o modelo de Bohr (figura 7), o protótipo foi feito com bandas pintadas de bolas de isopor representando as camadas (figura 8). Foram utilizadas bolas de isopor ocas e sobrepostas (uma dentro da outra) para a representação das camadas de energia. Para representar os elétrons, foi utilizado um cordão com miçangas recobertas de crochê ( figura 9), perpassando a ideia de que os elétrons não estão fixos em apenas uma camada e podem "saltar" de uma camada para outra.

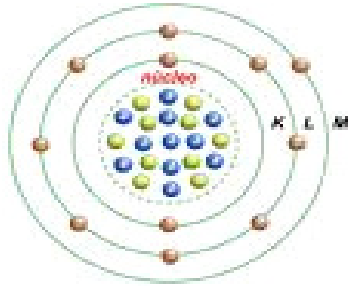

Figura 7. Modelo de Bohr. Fonte: 〈http://www mundoeducacao.com.br/ quimica/o-atomo-bohr.htm>.

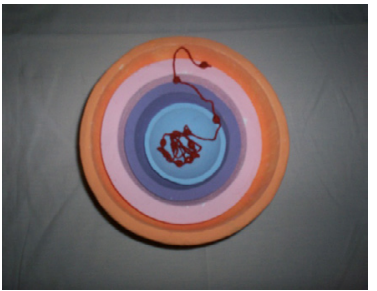

Figura 8. Foto que retrata o protótipo, bandas de isopor sobrepostas.

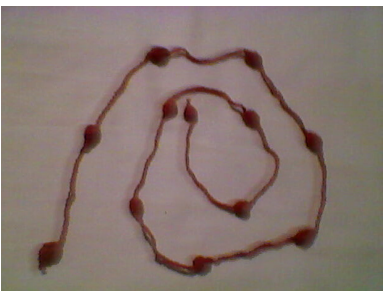

Figura 9. Foto que retrata o cordão com miçangas recobertas de crochê, representando os elétrons. 
Após a construção desses protótipos, foi feito uma experimentação / aplicação desses em uma escola de Ensino Médio da rede pública do Distrito Federal, na qual havia um único aluno cego, cursando o segundo ano do Ensino Médio. Tal aluno já havia estudado os modelos atômicos, porém, frequentemente citava não ter compreendido tal tema devido a falta de visualização de seus esquemas representativos. Assim, passamos a tentativa de elaboração dos protótipos e solicitamos à escola um espaço para que tais protótipos pudessem ser trabalhados com o aluno.

O encontro com o aluno foi realizado no espaço da escola e com a autorização da direção. A utilização dos protótipos ocorreu na sala de coordenação. Nesse encontro com o aluno estabeleceu-se conversações pertinentes a aprendizagem de Modelos Atômicos. Tal conversação foi gravada. Nessa oportunidade, iniciou-se a abordagem sobre modelos com a utilização da atividade "Imaginando o Invisível", conforme proposto por Santos, Mol et all (2005, p. 136). Nessa atividade, foi utilizada uma caixa lacrada contendo objetos que não podem ser vistos ou manuseados diretamente. A atividade tem o intuito de levar o aluno a tentar descrever as propriedades dos objetos contidos na caixa, mesmo sem vê-los ou tocá-los. Assim, pretende-se criar uma situação lúdica correlata a concepção de "modelos" - algo não visto mas construído a partir da interpretação dos fenômenos observados. Tal atividade contribui para o desenvolvimento do conceito de "modelo" como uma construção humana, algo que almeja representar uma teoria explicativa de um dado fenômeno.

Com o objetivo de verificar a formação do conceito de modelos, durante a atividade "imaginando o invisível", foi estabelecida uma conversação com o aluno, baseando-se, principalmente, em indagações sobre: quais os modelos o aluno já havia estudado, quando, quais recursos foram utilizados, qual o seu entendimento para "modelo", como descreve os modelos estudados e como acreditava que essa aprendizagem poderia ser facilitada.

Em seguida, passou-se a trabalhar com os protótipos construídos. Iniciouse pelo protótipo do modelo de Dalton, seguido por Thompson, Rutherford e Bohr, exatamente como na ordem histórica.

Os modelos não eram simplesmente apresentados pelo manuseio com os protótipos, mas eram discutidos com o aluno segundo uma perspectiva interativa / dialógica (AMARAL; MORTIMER, 2006), pois acredita-se que, dessa forma, a aprendizagem conceitual é favorecida. Como colocam Amaral e Mortimer (2006), na perspectiva interativa / dialógica, professores e alunos exploram ideias, fazem perguntas, dialogam e discutem pontos de vista.

Os resultados foram analisados a partir da interação com o aluno, seguindo uma perspectiva qualitativa. 


\section{Resultados e discussões}

Com o uso da atividade "Imaginando o Invisível" foi possível dar ênfase ao conceito de modelo e como este pôde ser criado. Tal atividade também propiciou uma preparação e conceituação importantes para o manuseio dos protótipos. Durante esta atividade, o aluno se mostrou participativo e com percepção aguçada em relação a propriedades dos materiais contidos na caixa, o que se pode verificar em sua fala:

Acho que é prego... eu acho... alguma coisa com barulhinho... moeda... alguma coisa metálica tem aqui dentro.

... porque quando eu balancei fez um barulhinho, tipo metálico ali dentro.

A partir das colocações feitas pelo aluno, conversou-se sobre as propriedades que ele conseguia identificar dentro da caixa, como por exemplo, a existência de metais. Embora os materiais não tenham sido vistos ou manuseados diretamente, o aluno criou hipóteses sobre os possíveis materiais, a partir da percepção de algumas propriedades conhecidas. Assim, foi possível fazer a associação com a criação dos Modelos Atômicos. Isto porquê, de acordo Simões e Soares (2009), nós construímos modelos para explicar o que não vemos ou o que não podemos tocar.

Para analisar o impacto dessa atividade na aprendizagem do aluno, identificamos em sua fala que o tema "Modelos Atômicos" já havia realmente sido estudado por ele. $\mathrm{O}$ aluno, inclusive, demonstrou que tinha familiaridade com o conteúdo, como pode-se observar:

Há tá! O livro que eu recebi lá da UnB... E nesses livros eu tava lendo... Como eu sou muito curioso, gosto de ler e tinha lá a parte do Thompson e desse primeiro... O Dalton, e tem o Rutherford, ai tinha os desenhos dos modelos atômicos deles lá. Só que não entendi muito bem, porque o desenho que eles fizeram, foi tipo... Eu não conhecia bem os modelos atômicos.

No trecho anterior, evidenciamos que os desenhos contidos nos livros já adaptados para o Braille não foram suficientes para o aluno ter entendimento sobre os Modelos Atômicos. Há outro momento na sua fala que faz referência à dificuldade de interpretar as figuras do livro:

Não, eu só fiquei sabendo desses modelos através da explicação dele e do livro que ele conseguiu, eu li e vi os desenhos, só que no livro os modelos não são tão explicadinhos como esses modelos aqui.

$\mathrm{Na}$ fala do aluno, é perceptível a dificuldade que ele teve com as figuras, que não ajudaram na percepção e na apropriação das informações sobre os modelos. Segundo Oliveira (2002), o emprego de desenhos, gráficos e cores nos livros modernos pode ser um fator dificultador para a transcrição para o Sistema Braille. Este fato praticamente obriga a adoção de soluções: como a adaptação do livro e transcrição em Braille ou a elaboração de livros especiais para cegos. A primeira solução pode acarretar perda de fidelidade quanto ao original e a segunda pode resultar em livros didáticos diferenciados para cegos e videntes em uma mesma classe. 
fascínio:

Durante o manuseio dos protótipos, identificou-se em sua fala surpresa e

Tão simples! Balão e a maisena e miçanga, faz uma coisa bem interessante... (Referência ao protótipo do Modelo Atômico de Thompson)

Como se fosse uma esfera de arame e que tem uns negocinhos, umas bolinhas de isopor.

Issoé uma biloca?

Eessas bolinhas? (Referência ao protótipo do Modelo Atômico de Rutherford).

Nesses trechos, fica evidente o interesse do aluno pela descoberta dos materiais enquanto os manuseava, o que contribuía para sua aprendizagem. Para Cerqueira e Ferreira (1996), talvez em nenhuma outra forma de educação os recursos didáticos assumam tanta importância como na educação especial de pessoas deficientes visuais, levando-se em conta que: alguns recursos podem suprir lacunas na aquisição de informações pela criança deficiente visual, além de o manuseio de diferentes materiais possibilitarem o treinamento da percepção tátil.

Seguindo a conversação sobre o Modelo de Bohr e a explicação sobre os elétrons ficarem livres em torno do núcleo, podendo mover-se nos orbitais, o aluno conclui a frase, como pode-se ver no trecho abaixo:

Pesquisadora: Aqui no centro seria o núcleo, mas o elétron não ficaria aqui, ficaria aqui em volta. Então cada vez que ele fosse excitado ele pularia para outra camada.

Aluno: e essas bolinhas?

Pesquisadora: Essas bolinhas seriam os elétrons, que ficariam aqui circulando nos orbitais.

Aluno: Há! Entendi!

Pesquisadora: e ai eles mudam, eles podem passar de um...

Aluno: voltando pra de cima quanto pra de baixo, quanto pra outra.

Pesquisadora: ele ta aqui em cima, ele vai voltar pra essa camada de energia aqui...

Aluno: Aî recebe energia... e emite luz.

A conversação estabelecida indica que o aluno, possivelmente, está se apropriando de tal conhecimento à medida que reproduz em sua fala o que estava pensando.

Como é demonstrado nos trechos seguinte, no qual novamente expressa sua ideia em relação à explicação sobre a mudança de camada de energia, o salto eletrônico e a emissão de luz. 
... Aí recebe energia... e emite luz.

... Há, então quando ele (o elétron) sobe não emite luz quando ele volta que vai emitir luz.

... Ou então, pode mais de um, aí significa que existem vários elétrons em um único átomo.

... Aí alguns podem saltar e outros continuar no mesmo lugar.

É possível inferir que o aluno tenta refletir sobre os modelos táteis e organizar seus pensamentos a respeito das novas informações que está recebendo. Dessa forma, é preciso que as informações que obtém com o manuseio e a explicação se complementem conjuntamente e não se transformem em informações isoladas e sem conexão. Para Oliveira, Biz e Freire (2003) o desenvolvimento sistemático da percepção tátil acoplada à aprendizagem é essencial para que os cegos cheguem a desenvolver a capacidade de organizar, transferir e abstrair conceitos.

No trecho seguinte, identifica-se que o aluno utiliza uma analogia para expressar que compreendeu o sistema de encaixe criado para representar as camadas de energia (Modelo Atômico de Bohr):

Como se fossem bacias, aí como se tivesse uma panelinha, aí vem uma bacia maior e outra maior ainda...

Nesse caso, a expressão de uma analogia pelo aluno reflete a apropriação do conhecimento, pois, quando ele consegue buscar uma analogia para expressar o seu entendimento, podemos inferir que ele compreendeu. Segundo Bozelli e Nardi (2008), muitas vezes os alunos recorrem ao uso da analogia no processo de interação comunicativa com o objetivo de comprovar o seu entendimento sobre o assunto tratado.

\section{Considerações acerca do uso dos modelos táteis e sugestões ou novas demandas}

Durante a conversação sobre o uso dos modelos táteis, foi questionado ao aluno sobre as contribuições de se utilizar esse tipo de recurso em sala de aula e como os protótipos dos Modelos Atômicos auxiliaram a aprendizagem do tema discutido, bem como qual a possibilidade de compreensão com o uso desses materiais em relação a conteúdos abstratos:

Ainda mais esse conteúdo que é muito, tipo complexo. E aí fica mais fácil a gente tendo uma ideia. Não é a ideia real, assim... Mas que a gente possa saber tipo, mexer com ele, pra saber como ele funciona, tal. Bem legal essa ideia.

De acordo com Dickman e Ferreira (2008), as dificuldades encontradas por estudantes cegos ocorrem, geralmente, nos conteúdos que se apóiam fortemente na visualização de fenômenos ou situações. Essas dificuldades podem ser freqüentemente contornadas pelo uso de protótipos, pois estes podem possibilitar o acesso a 
uma forma de percepção da imagem. O conteúdo de Modelos Atômicos tem intensa exploração visual. Entretanto, o aluno cego não pode fazer a associação do visual com a descrição presente nos livros didáticos. Portanto, a fala do aluno demonstra como os alunos cegos necessitam de um recurso didático para ajudá-los a conhecer e formular a imaginação baseada em um referencial que não seja apenas o que ouve ou lê. Em um momento de conversação, é possível comprovar a importância da elaboração de recursos pedagógicos para ser usado como referência quando se estuda um conteúdo relacionado com a visualização. No trecho a seguir, por exemplo, foi perguntado se o aluno conseguiria criar um modelo imaginário:

\section{Acho que sim. Mas eu teria que ter uma referência de alguma coisa pra} imaginar...

Portanto, os livros ajudam a compreender como é descrito um Modelo Atômico, mas para o aluno cego o ideal é que lhe seja possibilitado manusear e então se apropriar da informação por ter realmente experimentado, vivenciado.

Em outro trecho, foi questionado sobre o suporte fornecido pelos protótipos para sua compreensão e se o manuseio dos protótipos possibilitou um acréscimo de informações, de forma a facilitar a percepção de algo abstrato:

Com certeza! Eu vou conseguir compreender muito mais o conteúdo a partir de agora, depois desses modelos, vendo como é que eles são, assim de uma forma mais concreta, não tão abstrata, deu pra entender melhor!

Em sua fala o aluno inclusive utiliza a expressão "vendo", após ter a oportunidade de manusear os protótipos. Isso é extremamente significativo, pois expressa o quanto a atividade foi importante para a construção mental do significado de modelo e do entendimento das propostas apresentadas dos Modelos Atômicos. O aluno cego realmente tem sua visualização de uma forma diferenciada, a partir do manuseio, do tato, o aluno tem a percepção dos objetos e cria modelos mentais que substituem a visão direta, o que é chamado por Vygotsky (1997) de compensação.

No trecho seguinte, é possível verificar nas falas do aluno as contribuições dos protótipos dos Modelos Atômicos:

Com certeza, se tivesse essas explicações que vocês me deram aqui agora, teria aprendido muito mais.

O aluno com visão normal dispõe de todos os seus sentidos para auxiliá-los no acesso ao conhecimento, enquanto que o aluno cego precisa de recursos para que os seus outros sentidos sejam estimulados. O importante não é somente a disponibilidade do recurso, mas também é necessária uma conversação com o aluno sobre o material, caso contrário, os objetivos podem não ser alcançados, porque para o aluno sem informações sobre o que manuseia, o material não fará sentido algum. 
Em outros trechos é relatado sobre a contribuição dos modelos táteis para a compreensão dos conceitos relativos à atomicidade. Em seguida, é discutido sobre qual modelo foi mais significativo para o aluno e o que achou sobre a utilização dos protótipos. Então, o aluno faz referência ao modelo de Thompson, e se refere às miçangas utilizadas para representar aos elétrons como a "negoça".

Gostei, bastante! Foi muito legal. E foi uma ideia...de todos os modelos, foram ideias muito bacanas. Ainda mais aquele do balão com... a negoça... foi o que eu achei mais interessante. Porque deu pra saber tanto do lado de fora quanto do lado de dentro, o quê que acontece entendeu?

De acordo com Barreto, Resende Filho e Nascimento (2009), os estudos sobre os Modelos Atômicos utilizam-se da abordagem do nível simbólico, com o intuito de aproximar os alunos do respectivo conhecimento, concedendo uma concretude a conhecimentos abstratos característicos da Atomística, o que pode ser verificado na afirmação do aluno, sendo possível verificar que, com o manuseio dos modelos táteis, o aluno acessou um conteúdo puramente abstrato e de nível simbólico referente à descrição da constituição do átomo. Em outros trechos o aluno comenta sobre a possibilidade de utilização de recursos didáticos adaptados pelos professores:

Dessa forma sim, cada aula de química, cada conteúdo fosse feito, preparado com determinado tipo, de acordo... não só os modelos, mas outra parte... tipo de um jeito que eu pudesse tocar e entender as coisas, através do tato, entendeu?

Em seguida, o aluno comenta sobre a possibilidade de utilização de tais materiais para contribuir na aprendizagem de todos:

E não só a gente que não enxerga, mas o pessoal que vê também! Fica mais fácil para eles!

Com esse comentário, é possível considerar que todos possuem tempos diferentes para aprender, independentemente de características físicas ou sensoriais. O que principalmente diferencia o ensino é o modo como o professor trabalha com essas diferenças em sala de aula. Para Bertalli (2008), materiais adaptados não devem ser utilizados somente por alunos cegos, muitos alunos com a visão normal também podem se favorecer com o uso de tais materiais, considerando-os mais atrativos e pedagógicos que o livro didático. Tal fato mostra que um material didático bem adaptado pode ser mais bem aproveitado por todos os alunos e não somente por alunos com deficiência visual, promovendo a não exclusão e a interação entre todos. Contudo, considera-se que os recursos didáticos adaptados contribuem para a aprendizagem, favorecendo a apropriação do conhecimento de forma mais significativa, assim como a possibilidade de inclusão.

\section{Considerações finais}

Atualmente, a inclusão é algo muito comentado, mas isso não significa que seja algo simples e que realmente aconteça nas escolas. Os professores ainda afirmam estar despreparados para receber alunos com necessidades educacionais especiais e costumam atribuir a tarefa de ensiná-los à sala de recursos (atendimento educacional 
especializado). Porém, a proposta inclusiva é totalmente diferenciada dessa situação. Em um espaço inclusivo os alunos especiais devem se sentir e se tornar parte da turma. Assim, é também papel do professor promover a inclusão. Dessa forma, não é o aluno que se adapta à aula, mas o professor deve adaptar suas aulas de acordo com as características de seus alunos, buscando alternativas para a aprendizagem de todos.

A situação de exclusão de alunos especiais em sala de aula, possivelmente, está relacionada ao despreparo dos professores, ocasionado por cursos de formação que não possuem foco de trabalho no ensino especial. Esse despreparo é evidente no ensino de cegos, no qual existe um enorme preconceito sobre a capacidade de aprendizagem desses alunos. Assim, este trabalho foi desenvolvido em um curso de formação de professores de Ciências, almejando proporcionar, aos licenciandos, oportunidades de vivências significativas quanto a inclusão.

De forma geral, percebemos que os professores se apóiam no livro didático como ferramenta principal para o ensino, o que não privilegia os alunos com necessidades educacionais especiais. Os livros adaptados seriam uma solução, porém, as vezes a adaptação do conteúdo se torna complexa e de difícil compreensão.

Com o uso de materiais adaptados (como os protótipos) é verificado que quando são oferecidas, ao aluno cego, vias de ensino que não explora o visual, seu desempenho é satisfatório. O manuseio de um material adaptado possibilita ao cego visualizar através do tato, funcionando como um referencial para que possa construir mentalmente uma imagem, o que exalta a necessidade de o professor levar para a sala de aula recursos didáticos concretos.

Ao utilizar tais recursos didáticos, o professor propõe uma metodologia diferenciada. Obviamente deve haver uma exploração sobre o material, características que o representam e limitações. Mas, vale ressaltar a necessidade de deixar que os alunos cheguem a conclusões, dando espaço para que explorem suas idéias sobre o assunto. No diálogo, é importante fazer com que o aluno verbalize o que está compreendendo sobre o material, suas percepções pessoais. A verbalização o ajuda a organizar as informações, o que faz com que intensifique a apropriação do conhecimento, considerando que aprender é dialogar com a palavra do outro.

\section{Referências}

AMARAL, E. M. R. ; MORTIMER, E. F. . Uma metodologia para análise da dinâmica entre zonas de um perfil concitual no discurso da sala de aula. In: SANTOS, F. M. T.; GRECA, I. M. (Org.). A pesquisa em ensino de ciências no Brasil e suas metodologias. 1 ed. Unijuí: Editora Unijuí, p. 239-296, 2006.

BARRETO, I. S.; RESENDE FILHO, J. B. M.; NASCIMENTO, Y. I. F. Ensino de Química e Inclusão: Confecção de Modelos Atômicos que facilitem a aprendizagem de alunos Deficientes Visuais. Anais. $7^{0}$ Simpósio Brasileiro de Ensino de Química, Salvador, BA, 2009.

BERTALLI, J. G. Ensino de Química para deficientes visuais. Anais: XIV Encontro Nacional de Ensino de Química, Paraná, 2008. 
BOZELLI, F. C., NARDI, R. O uso de analogias no processo comunicativo de Sala de Aula. Anais: XI Encontro de Pesquisa em Ensino de Física, Curitiba, PR, 2008.

BRASIL. Câmara dos Deputados. Lei de Diretrizes e Bases da Educação Nacional - LDB - Lei n. 9.394 de 1996. Brasília: Câmara dos Deputados, 1997.

BRASIL, Ministério da Educação - Secretaria de Educação Especial (SEESP). Política nacional de educação especial na perspectiva da educação inclusiva. Brasília: MEC, 2008.

BRASIL, Diretrizes nacionais para a educação especial na educação básica. Disponível em: ‘http://portal.mec.gov.br/seesp/arquivos/pdf/salamanca.pdf.> Acesso em: 17 jul. 2010.

CAMPOS, I. M.; SÁ, E. D.; SILVA, M. B. C. Atendimento Educacional Especializado - Formação Continuada a Distância de Professores para o Atendimento Educacional Especializado. Deficiência Visual. SEESP / SEED / MEC. Brasília. 2007.

CERQUEIRA, J. B.; FERREIRA, M. A. Os recursos didáticos na educação especial. Revista Benjamin Constant, Rio de Janeiro, n. 5, 1996.

BRASIL. Declaração de Salamanca. Disponível em: «http://portal.mec.gov.br/seesp/arquivos/pdf/salamanca.pdf.> Acesso em: 17 jul. 2010.

DICKMAN, A. G., FERREIRA, A. C. Ensino e aprendizagem de Física a estudantes com deficiência visual: Desafios e Perspectivas. Revista Brasileira de Pesquisa em Educação em Ciências, v. 8, n. 2, 2008.

FREITAS,D.; ZANON, D.A.V. A aula de ciências nas séries iniciais do ensino fundamental: ações que favorecem a sua aprendizagem. Ciências e Cognição, v. 10, p. 93-103, 2007.

MEC/SEESP Política Nacional de Educação Especial na Perspectiva da Educação Inclusiva. Disponível em: 〈http://portal.mec.gov.br/seesp > Acesso em: 17 jul. 2010.

OLIVEIRA, F. I. W. A Importância dos Recursos Didáticos Adaptados no Processo de Inclusão de Alunos com Necessidades Especiais. Disponível em: ‘http://www.unesp.br/prograd/PDFNE2002/aimportanciadosrecdidaticos.pdf>Acesso em: 30 mar. 2011.

OLIVEIRA, F. I. W.; BIZ, V. A.; FREIRE, M. Processo de Inclusão de Alunos Deficientes Visuais na Rede Regular de Ensino: Confecção e Utilização de Recursos Didáticos Adaptados. Disponível em:<(http://www.unesp.br/prograd/PDFNE2003/Processo\%20de\%20inclusao\%20de\%20alunos\%20deficientes\%20visuais.pdf)>. Acesso em: 30 mar. 2011.

PIRES, R. F. M.; RAPOSO, P. N.; MÓL, G. S. Adaptação de um livro didático de Química para alunos com deficiência visual. Anais, VI Encontro Nacional de Pesquisa em Educação em Ciências, 2007, Florianópolis, SC, 2007.

RETONDO, C. G. \& SILVA, G. M. Ressignificando a Formação de Professores de Química para a Educação Especial e inclusiva: Uma História de Parceria. Química Nova na Escola, n. 30, p. 27-33, 2008.

SANTOS, M. J. A escolarização do aluno com deficiência visual e sua experiência educacional. Dissertação de Mestrado, Universidade Federal da Bahia: Salvador-BA, 2007.

SANTOS, W. L. P.; MOL, G. S. (Coord.). Química e Sociedade: volume único, ensino médio. 1. ed. São Paulo: Editora Nova Geração, p. 744. 2005.

SIMOES, E., SOARES, E. C. A Construção de Modelos Atômicos no Ensino de Química. Anais. 17º Seminário Educação, Mato Grosso, MT, 2009.

VYGOTSKY, L. S. Obras Escogidas. Volume V, Fundamentos de Defectologia, Madrid: Visor, 1997.

Revista Educação Especial | v. 27 | n. 48 | p. 141-154 | jan./abr. 2014

Santa Maria 


\section{Correspondência}

Renata Cardoso de Sá Ribeiro Razuck - Universidade de Brasília, Campus Planaltina, Faculdade UnB Planaltina, CEP: 73061-000, Planaltina, Brasília, Distrito Federal, Brasil.

E-mail: renatarazuck@unb.br - loraineborges85@yahoo.com.br

Recebido em 23 de novembro de 2012

Aprovado em 03 de maio de 2013 